\title{
The application of big data in the performance evaluation of private colleges and Universities
}

\author{
Yuan Quan ${ }^{1 \mathrm{a}}$, Junfeng Wang ${ }^{1 \mathrm{~b}}$, Shuwen $\mathrm{Li}^{1 \mathrm{c}}$, Wang Dan ${ }^{1 \mathrm{~d}}$ \\ ${ }^{1}$ Dalian university of science and technology College of Economic and Managementline dalian, liaoning
}

\begin{abstract}
The rapid development of big data has brought new opportunities for the operation and development of private colleges and universities. As an important way for private colleges and universities to assess teachers' work, performance evaluation is not only an important guarantee for promoting teachers' work, but also an important influencing factor for private colleges and universities to stand for a long time. There are some problems in the traditional way of university performance evaluation. This paper will further explore the specific application of big data in the performance evaluation of private universities based on its application characteristics.
\end{abstract}

\section{Introduction}

In recent years, big data has been widely used in all walks of life, education industry is no exception, many private colleges and universities have applied big data to performance evaluation. To a great extent, it improves the scientificity and comprehensiveness of performance evaluation.

\section{The current situation of performance evaluation of private colleges and Universities}

Most of the private colleges and universities adopt the traditional assessment management system and method, which is mainly based on "morality, ability, diligence, performance and honesty", combined with the workload of teachers and the quality of teaching work. But in fact, with the development of society, the definition standard of talents is higher and higher. As an important base for training talents, colleges and universities will put forward higher requirements for teachers. So the traditional performance evaluation can not measure the performance of teachers comprehensively and carefully. The traditional way of performance evaluation is mostly mutual evaluation. Many teachers focus on scientific research and teaching, ignore interpersonal relationship, and often get lower scores. They can't achieve real fairness and justice, which loses the original intention of encouraging teachers to participate in teaching and scientific research through performance evaluation. The assessment objective is too vague to refine the performance, which often results in a large workload and a mere formality of performance statistics, so it can not be evaluated according to the actual work of teachers. And the performance evaluation data is completely closed, teachers can not get good feedback, so they can not find their own reasons for self-improvement.
In this system, it is inevitable to affect the enthusiasm of teachers, thus affecting the improvement of the overall level of teachers.

\section{Problems in performance evaluation of private colleges and Universities}

With the strong support of national policies, the development momentum of private colleges and universities is getting better and better, with more and more students. In accordance with the requirements of the national regulations on the ratio of teachers to students of private colleges and universities of $1: 18$, the number of teachers is also growing, and the performance evaluation work has become quite heavy. Using traditional performance evaluation methods has been unable to comply with the development trend of private colleges and universities. Now, the problems of traditional performance evaluation are summarized as follows:

\subsection{Data collection is too complicated}

The common part of the performance evaluation of private colleges and universities mostly uses the form of paper "filling in forms" to submit performance data, and the performance accounting personnel need to input a large number of data into electronic forms. In the process of performance mutual evaluation, we continue to "fill in the form" and add a lot of data entry work for performance accounting personnel. Even if the accounting personnel make the form more detailed, it is difficult for the managers to understand the performance of each teaching staff at a glance. Without the accounting personnel's explanation, others cannot understand the calculation process of the assessment data. Even the workload and quality of work calculated by quantification are first "filled in form", and then checked one by one by special staff. The workload is very huge, and it is 
extremely easy to make mistakes. In order to be foolproof, it needs to be reworked many times, checked many times, and the efficiency is extremely low.

\subsection{Unreasonable formulation of assessment indicators and unclear objectives}

The content of traditional assessment method is too general, and individual common indicators are overlapping, and the same assessment method is adopted regardless of position, title and specific position. Some teachers are good at teaching, some are good at scientific research, and some are committed to innovation and entrepreneurship......The existing performance evaluation methods do not vary from person to person. They can not measure each person's specific work situation well. They are unfair and can not play an incentive and alerting role. In this way, the most important significance of performance evaluation is lost and the brain drain is likely to be caused.

\subsection{Performance evaluation is too formal and lacks reasonable feedback mechanism}

The purpose of performance evaluation should be to find out the merits and demerits of each teacher from the assessment results, and to "change the dross and promote its essence", so as to provide objective basis for teachers' promotion, evaluation and training, and promote the overall development of the school. However, after the traditional performance evaluation, if the teachers have no objection to the evaluation results, they will not feed back the evaluation data to every teacher. Only the last few teachers' leadership will choose to interview, and the leaders will not point out the problem too pertinently in order to take care of their faces. So the vast majority of teachers can not find their own problems in performance evaluation, which has become just for evaluation.

\section{How to use big data to improve the performance appraisal mechanism of private university teachers}

With the development and application of big data, changing the traditional performance appraisal method has become one of the most important issues for private colleges and universities. The performance evaluation of private colleges and Universities Based on big data should be improved from the following aspects:

\subsection{Static data acquisition to dynamic data acquisition}

The transformation of performance data collection mode is mainly realized through the integration of dynamic data sources on the Internet, so as to ensure the accuracy of data collection. Private colleges and universities can realize the transformation from static data collection to dynamic data collection by introducing relevant performance evaluation system. Most performance appraisal systems are web-based, easy to operate and not limited by time and place. At the beginning of the year, each teacher enters the assessment data into the system according to his own assessment system, and then enters the assessment completion status into the system at the end of the year, so that the system can calculate the performance data by itself. Data accounting personnel only need to export data of all employees in the background at one time, which not only makes the assessment data clear at a glance, improves the efficiency and accuracy of data calculation, but also greatly reduces the workload of data accounting personnel.

\subsection{From single evaluation system to multi evaluation system}

This is mainly to rely on the Internet to reconstruct the inherent evaluation platform to ensure the overall positioning and personalized index setting of each evaluation object. First, the personnel department uses the performance evaluation system to input the common part into the system and set the authority, and then sends the account number to each teacher. According to the system prompt, teachers input their own relevant data into the system, Create a "360 degree" personal portrait, Use big data technology to analyze the characteristics of each teacher, use advanced statistical technology to establish a model, and automatically generate an evaluation rule. The teacher then adjusts according to the rule, makes his own best performance evaluation scheme, and then submits it to the leader for approval and modification, the personnel department for review, and finally returns it to the staff for confirmation, forming a closed chain, and truly achieving "quantity" Personal customization ", to achieve the greatest degree of fairness and rationality, not only can cultivate the sincerity of employees, but also can attract new talents to the greatest extent.

\subsection{Realize the multi-dimensional evaluation of private colleges and Universities}

This is mainly through big data algorithm, fully mining the internal relationship between private colleges and universities, analyzing the rationality of performance evaluation of colleges and universities, so as to ensure the scientificity of performance evaluation. If all the civilian colleges and universities can use the big data performance evaluation system, they can calculate more suitable evaluation indexes for each teacher by comparing the advantages and disadvantages, school running objectives, school running ideas and so on, which greatly reduces the workload of the personnel department. And the performance evaluation system has set up the account authority, the system only uses the data mining technology to analyze and process the data, will not make the information leak, and ensure the security of the information of each university. 


\subsection{Single data feedback to interactive communication feedback}

The development of big data can improve the ability of performance appraisal system in data mining, storage, processing and analysis, enhance the ability of data transmission and data screening, and make use of Internet technology with distributed and point-to-point nature as support. It can make the data flow of performance appraisal platform of private colleges and universities change from single to two-way interaction, and ensure the gradual trend of performance appraisal In rationalization and perfection. Through the use of big data performance appraisal system, teachers and staff can clearly understand the completion of each part of their performance. Through the Internet platform, it is convenient for teachers and staff to exchange information with leaders, avoid the embarrassment of face-to-face conversation, enable leaders to give performance feedback to each employee, reduce the negative emotions of teachers and staff, and thus reduce the tendency to quit. Let employees stand in the position of leaders to understand their own shortcomings, and carry out modification and promotion.

\subsection{From result evaluation to process evaluation.}

The transformation of this evaluation method can greatly enhance the work enthusiasm of the evaluated object and tap its development potential. Each faculty member can review the achievements and gaps in the past year through big data performance appraisal system, and use big data algorithm to mine their own advantages, further develop their own advantages, and specify aspects for career planning. From the school point of view, we can better understand each teacher's special projects according to big data analysis, and use them because of talent, which brings inestimable effect to the development of the school, and makes the performance evaluation really meaningful.

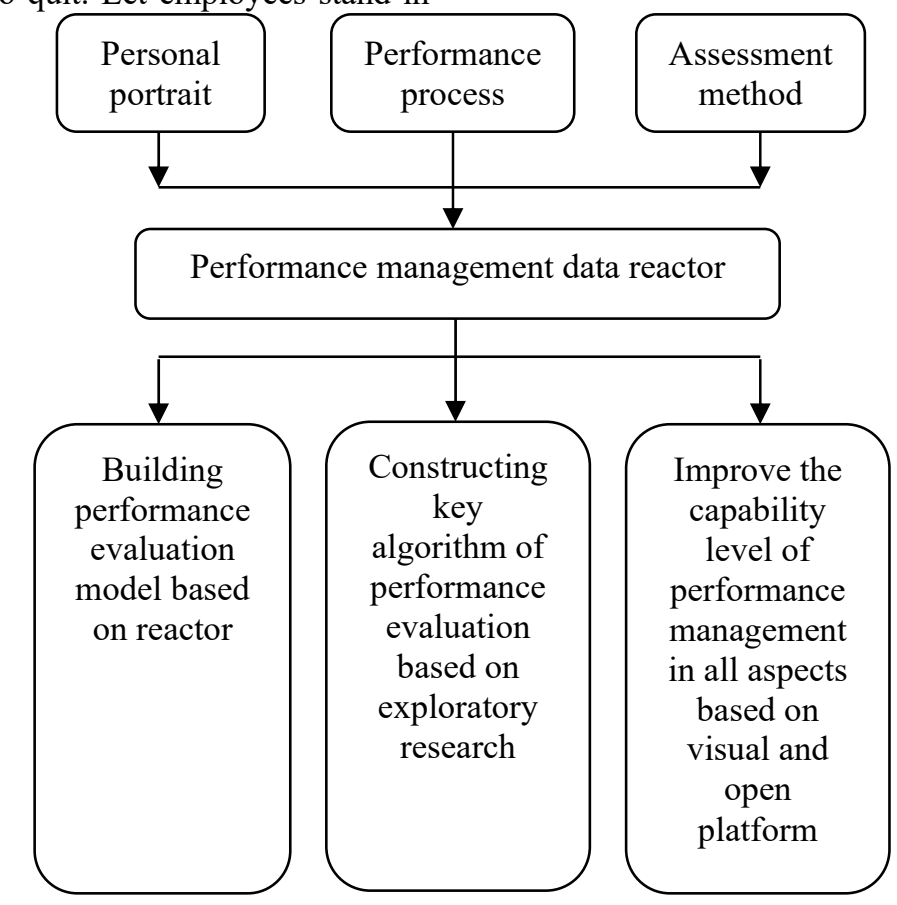

Figure 1. Construction chart of performance evaluation systembased on big data

\section{The specific application of big data in the performance evaluation of private colleges and Universities}

\subsection{Using big data to improve performance evaluation index system}

In the era of big data, there are massive data in human resource management that can provide services for the development of performance evaluation. Under the concept of data processing and analysis, talent development is based on all data. The performance evaluation based on big data can quantify the data and discard the disturbed data, which makes the process of performance evaluation more targeted and persuasive. In the specific data processing and analysis process, colleges and universities can make a comprehensive evaluation of talents through the basic data, ability data, efficiency data and potential data of faculty. Through these "personal information" which can truly reflect the quality of teaching staff, to help teaching assistants have a better understanding of the job, is also an important basis for the evaluation of personal development expectations.

The traditional performance evaluation of colleges and universities mostly relies on quantitative indicators, which is relatively single and lack of scientific. Under the background of big data, the performance evaluation system of colleges and universities has gradually changed from a single quantitative standard to a multiple evaluation system combining quantitative and qualitative. In short, when evaluating teachers' performance, we should not only pay attention to their teaching level, scientific research ability and other hard indicators, but 
also comprehensively consider the quality of teachers' scientific research achievements and the interaction between teachers and students. In the context of big data, private colleges and universities can make full use of big data, subdivide the assessment indicators into visual and detailed evaluation methods and dimensions, form a set of data-based performance assessment system in combination with the actual situation of private colleges and universities, refine the work through big data technology, reasonably set the weight of relevant indicators, and build the performance of private colleges and Universities Based on big data The final assessment grade is given by weighting method. And it can make full use of the advantages of big data and Internet to ensure the rapidity and comprehensiveness of data information collection and further ensure the objectivity, fairness and scientificity of performance evaluation. For example, with the support of big data technology, process assessment becomes possible. Private colleges and universities can use cartoon, information-based teaching platform and other forms to comprehensively grasp the attendance of teachers and the interaction with students. In addition, it can also test the value of teachers' scientific research achievements, rather than roughly evaluate teachers' scientific research ability based on traditional quantitative indicators. To a great extent, it can ensure the scientificity of performance evaluation and effectively urge teachers' enthusiasm.

\subsection{Using big data to realize information sharing and data co construction}

At present, most private colleges and universities have their own digital campus, but because it is still in the initial stage of construction, there are still some problems. For example, there are some problems such as the information between information systems can not be shared, and the function design is not comprehensive. However, in the process of data collection, performance appraisal needs to involve data of multiple information systems. This kind of design, which is lack of humanity and practicality, will increase the difficulty of performance appraisal data collection. Therefore, many private colleges and universities have used big data technology to open data channels among various information platforms, making data sharing and co construction possible. With the support of cloud computing and other technologies, they have realized the rapid integration and analysis of data. On the basis of the performance appraisal system based on big data, private colleges and universities are also gradually realizing the establishment of personal database of teachers, and then through the directional mining and analysis technology of big data to match the development of teachers and universities, forming a recommendation platform for data collection and online analysis, forming a complete analysis of points, lines and surfaces, and using data to personally send teachers Overall analysis of the exhibition. Ensure the rationality of performance evaluation.

\subsection{Using big data to establish the feedback mechanism of early warning and evaluation}

The effective combination of data collection and analysis can help universities eliminate useless data and interference data in the process of performance evaluation, and enhance the effectiveness and authenticity of evaluation data. To the greatest extent, it can ensure the horizontal comparison and vertical evaluation of teachers' performance data, and effectively realize the early warning and evaluation role in the process of teachers' self-development. The original intention of performance appraisal in private colleges and universities is to further promote the common growth and synchronous development of schools and teachers. The establishment of feedback mechanism of early warning and evaluation is conducive to promoting mutual supervision and encouragement among departments and teachers, and stimulating teachers' working motivation and potential.

\subsection{Using big data to improve teachers' information awareness and ability}

The application of big data in the performance evaluation of private colleges and universities will naturally put forward higher requirements for the informatization level and ability of schools and teachers. Campus informatization is also the inevitable development trend of private colleges and universities in the future. Private colleges and universities will gradually introduce more and more new informatization equipment and equipment. Teachers, as the first practitioners of informatization technology and equipment in Colleges and universities, must strengthen the awareness of informatization and gradually improve the ability of informatization management. The application of big data in the performance appraisal of private colleges and universities can effectively help teachers to deepen their understanding of big data and information technology, and lay an information foundation for their future work.

\section{Conclusion}

In the era of big data, the performance appraisal based on data processing and analysis can efficiently find the information matching the personal evaluation needs in the massive performance evaluation data. The combination of performance appraisal and big data in private colleges and universities is the inevitable choice for the sustainable development of colleges and universities, as well as the inevitable requirement for colleges and universities to comply with the times to assess teachers' teaching level and comprehensive ability. Private colleges and universities should actively summarize the potential problems in the performance appraisal, gradually improve the performance appraisal standard system by using big data, and establish an effective early warning and evaluation mechanism to lay a good foundation for the informatization construction of the performance appraisal of private colleges and universities. The Internet plus thinking is used to build a database resource platform of its own. It analyzes the data of the demand for talents in private universities, and excavates the value behind the 
data, so as to effectively promote the sustainable development of private colleges and universities.

\section{References}

1. Xu Yan. Innovation of enterprise human resource performance management in the era of big data $[\mathrm{J}]$. Jiangxi Social Sciences,2016, pp18-17.

2. Shi Shiqiang. Research on human resource performance management innovation in the era of big data $[\mathrm{J}]$, marketing circle, December 2019, pp108+ 121

3. Guo Jinghong, Su Peiyao, Lin Rongmao, research on the influence of data literacy of university counselors on work performance under the background of big data, information recording materials. 2019,7,pp6269.

4. Jiang Xue. Application and innovation of human resource management based on big data [J], science, education and culture, 2018, 9, pp78-79.

5. Zhan Yan. Innovation and challenge of human resource management application in the context of big data $[\mathrm{J}]$, human resource management, 2017, 9, pp40-41.

6. Wang Jing. Exploration of enterprise human resource management innovation in the era of big data [J], South entrepreneur, 2018, 3,pp106-107.

7. Wang Shumin. Innovation of human resource performance management in enterprises and institutions under the background of big data [J]. Human resource development, 2020, 3, pp42-43.

8. Zhao Yi. An analysis of the intelligence of human resource management in Colleges and universities [J]. Higher education research, Southwest University of science and technology, 2020,3, pp27-31 + 74 .

9. Chen Xiangyu. Human resource management reform in Higher Vocational Colleges in the era of big data [J]. Human resource development.,2020, 2, pp12-24.

10. Chen Di. Research on innovation strategy of scientific research management in Universities under the background of big data [J]. Journal of Hunan University of science and technology. 2019, 11, pp94-95 